\title{
Study on the Warning of Giant Jellyfish Disaster in the Coastal Waters of Qingdao
}

\author{
LingJuan Wu, Tao Bai, Guiyan Liu
}

North China Sea Marine Forecasting Center of State Oceanic Administration, Qingdao 266061, China

\section{青岛近海水母灾害预警方法研究}

\author{
吴玲娟 白涛 刘桂艳
}

国家海洋局北海预报中心, 青岛 266061, 中国

\begin{abstract}
:
In this paper, with reference to emergency response and warning standard of marine ecological disaster such as red tide and green tide, the methods of external giant jellyfish disaster warning in the coastal waters of Qingdao have been studied according to jellyfish species, toxicity, distribution density, location and the possible arrival time for warning waters. According to their different characteristics, jellyfish disaster warning on bathing beach and water intake of power plant is divided into four levels, respectively, which represents different warning level with red, orange, yellow, and blue. Finally, this method has been demonstratively applied in the coastal waters of Qingdao.
\end{abstract}

Keywords: giant jellyfish disaster, warning, bathing beach, water intake of power plant

\section{摘要}

本文借鉴赤潮和绿潮等海洋生态灾害应急响应和预 警报标准, 根据灾害水母种类、水母毒性、水母分布 密度等指标, 结合水母发生区域和可能到达预警区时 间, 研究青岛近海外来型水母灾害预警方法。根据青 岛海水浴场和电厂取水口不同特征, 将水母灾害警报 分为 4 个等级, 并分别用红、橙、黄、蓝等四种颜色 表征其预警程度，并在青岛近海示范应用。

关键词: 大型水母灾害 预警方法 海水浴场 电厂取 水口

\section{1. 引言}

在全球气候变化和人类活动影响下, 海洋生态系统的 结构与功能发生了很大变化, 大型水母灾害发生频率 与成灾种类不断增加, 已严重影响了近海海洋渔业、 沿海工业、滨海旅游业和海洋生态系统[1-5]。国内外 水母灾害预警工作主要基于水母灾害监测信息对水 母灾害进行预测和预警。韩国基于济州岛附近海域水 母水母监测方法研究, 于 2011 年正式建立水母监测 体系, 为预测水母运动趋势等提供重要信息。日本利 用船舶、遥感、浮标等多源监测手段, 随时获取海域 大型水母的分布情况, 经过汇总和处理成为视化的水 母实时分布与预报信息, 及时发布给渔民和其它用海 群众[6,7]。美国 NOAA 等研发太平洋黄金水母出现 概率长期预报系统, 定期发布水母预警报 [8]。2012 年, 法国滨海自由城海洋实验室基于 Berline 等水母 漂移模式[9]和监测结果, 推出从马赛到芒通、从圣 特罗佩到意大利边境的滨海海滩 48 小时在线水母预 警系统, 并在 Medazur 和 jellywatch(http://www. jelly watch.org/) 两家网站发布水母预报和分等级的警报, 对各海滩的水母威胁程度进行打分, 最低零分代表无 危险, 最高五分代表高度危险。

近年来, 青岛近海大型水母连年暴发, 成灾种类 主要有海月水母、沙海哲和白色霞水母。王世伟等 [10]、孙松等[11]和张海彦等[12]的监测和研究结果认 为青岛近海海月水母主要分布于胶州海湾内, 能够在 湾内自行自我补充并完成其生活史, 可能属于原发 型; 沙海掹和白色霞水母可能不是由本地水螅体和水 母幼体发育, 属于外来型的。国内外科学家水母灾害 预测预警方面的研究和工作偏重于预测, 对如何制定 水母灾害预警没有具体的标准。本文借鉴赤潮、绿潮 
Risk Analysis and Crisis Response in Big Data Era (RAC-16)

等比较成熟的海洋生态灾害预警标准, 针对外来型水 母灾害, 基于水母种类、毒性、水母灾害监测数据和 水母漂移预测结果等对青岛近海外来型水母预警方 法进行初步研究, 并在青岛近海示范应用。

\section{2. 国内海洋灾害应急响应及预警报标准}

借鉴国内海洋生态灾害（绿潮、赤潮等）应急响应及 预警报标准, 结合水母灾害特征, 初步建立了水母灾 害风险等级预警方法。

\section{1. 赤潮灾害标准和应急响应}

按照赤潮灾害发生的影响范围、性质和对人类和 敏感危害程度, 赤潮灾害分为特别重大赤潮灾害、重 大赤潮灾害、较大赤潮灾害和一般赤潮灾害四级 (表 1）启动相应的一级、二级、三级和四级应急响应。

\section{2. 青岛市大型藻类预警标准}

根据绿潮所在位置、分布面积、覆盖面积和未来 三天影响区域等指标, 海洋大型藻类灾害预警级别分 为 I 、II、III、IV四级警报, 颜色依次为红色、橙色、 黄色和蓝色 (表 2)。

表 1 赤潮灾害标准

\begin{tabular}{|c|c|c|c|c|}
\hline \multirow[t]{2}{*}{ 指标 } & \multicolumn{4}{|c|}{ 赤潮灾害标准 } \\
\hline & $\begin{array}{c}\text { 特别重大赤潮灾 } \\
\text { 害 } \\
\end{array}$ & 重大赤潮灾害 & 较大赤潮灾害 & 一般赤潮灾害 \\
\hline $\begin{array}{c}\text { 近岸海域赤潮 } \\
\text { 面积 (平方公 } \\
\text { 里) }\end{array}$ & $\begin{array}{l}\geqslant 5000 \text { (无毒); } \\
\geqslant 3000 \text { (有毒) }\end{array}$ & $\begin{array}{c}3000<\text { 面积 }<5000 \\
\text { (无毒); } 1000<\text { 面 } \\
\text { 积 }<3000 \text { (有毒) }\end{array}$ & $\begin{array}{l}1000<\text { 面积 }<3000 \\
\text { (无毒); } 500<\text { 面积 } \\
<1000 \text { (有毒) }\end{array}$ & $\begin{array}{c}\text { 面积 }<1000 \text { (无 } \\
\text { 毒); 面积 }<500 \\
\text { (有毒) }\end{array}$ \\
\hline $\begin{array}{l}\text { 近岸以外赤潮 } \\
\text { 海域 (平方公 } \\
\text { 里) } \\
\end{array}$ & $\begin{array}{l}\geqslant 8000 \text { (无毒); } \\
\geqslant 5000 \text { (有毒) }\end{array}$ & $\begin{array}{c}5000<\text { 面积 }<8000 \\
\text { (无毒); } 3000<\text { 面 } \\
\text { 积 }<5000 \text { (有毒) }\end{array}$ & $\begin{array}{l}3000<\text { 面积 }<5000 \\
\text { (无毒)； } 1000<\text { 面 } \\
\text { 积 }<3000 \text { (有毒) }\end{array}$ & $\begin{array}{c}\text { 面积 }<3001 \text { (无 } \\
\text { 毒); 面积 }<1000 \\
\text { (有毒) }\end{array}$ \\
\hline $\begin{array}{l}\text { 对人类影响 (因 } \\
\text { 食用受赤潮污 } \\
\text { 染的水产品或 } \\
\text { 接触到赤潮海 } \\
\text { 水) }\end{array}$ & $\begin{array}{l}\text { 身体严重不适病 } \\
\text { 例报告 } 100 \text { 人以 } \\
\text { 上, 或出现死亡 } \\
\text { 人数 } 10 \text { 人以上 }\end{array}$ & $\begin{array}{l}\text { 出现身体严重不适 } \\
\text { 病例报告 } 50 \text { 人以 } \\
\text { 上、 } 100 \text { 人以下或死 } \\
\text { 亡人数 } 5 \text { 人以上 } 10 \\
\text { 人以下; }\end{array}$ & $\begin{array}{l}\text { 出现身体严重不适 } \\
\text { 病例报告超过 } 10 \text { 人 } \\
\text { 以上、 } 50 \text { 人以下, 或 } \\
\text { 出现死亡人数 } 5 \text { 人以 } \\
\text { 下 }\end{array}$ & 无影响 \\
\hline 对海域的影响 & $\begin{array}{l}2 \text { 天内可能影响 } \\
\text { 社会敏感海域 } \\
\text { (如重大活动海 } \\
\text { 域), 或 } 2 \text { 天内可 } \\
\text { 能影响经济敏感 } \\
\text { 海域并可能造成 } \\
5000 \text { 万元以上的 } \\
\text { 经济损失。 } \\
\end{array}$ & $\begin{array}{c}5 \text { 天内可能影响社 } \\
\text { 会敏感海域 (如重 } \\
\text { 大活动海域), 或 } 2 \\
\text { 天内可能影响经济 } \\
\text { 敏感海域并可能造 } \\
\text { 成 } 5000 \text { 万元以上的 } \\
\text { 经济损失。 }\end{array}$ & $\begin{array}{l}10 \text { 天内可能影响社 } \\
\text { 会敏感海域 (如重大 } \\
\text { 活动海域), 或 } 2 \text { 天 } \\
\text { 内可能影响经济敏 } \\
\text { 感海域并可能造成 } \\
1000 \text { 万元以下经济 } \\
\text { 损失。 }\end{array}$ & 无影响 \\
\hline
\end{tabular}


Risk Analysis and Crisis Response in Big Data Era (RAC-16)

表 2 青岛市大型藻类预警标准

\begin{tabular}{|c|c|c|c|c|}
\hline \multirow[t]{2}{*}{ 指标 } & \multicolumn{4}{|c|}{ 青岛市大型藻类预警标准 } \\
\hline & I 级预警（红色） & II 级预警（橙色） & III级预警（黄色） & IV级预警（蓝色） \\
\hline 海洋大型藻类 & 分布面积 $\geqslant 8000 ;$ & 分布面积？7000 & 分布面积？5000 & 分布面积？3000 \\
\hline $\begin{array}{l}\text { 面积 (平方公 } \\
\text { 里) }\end{array}$ & 覆盖面积 $\geqslant 500$ & $\begin{array}{c}300 \leqslant \text { 覆盖面积 }< \\
500\end{array}$ & $\begin{array}{c}100 \leqslant \text { 覆盖面积 }< \\
300\end{array}$ & 覆盖面积>50 \\
\hline $\begin{array}{c}\text { 聚集区分布情 } \\
\text { 况 }\end{array}$ & $\begin{array}{l}\text { 主要分布在大公岛与竹 } \\
\text { 岔岛连线以北、团岛以 } \\
\text { 东、石老人海水浴场以 } \\
\text { 西的青岛市区南部海域 }\end{array}$ & $\begin{array}{c}\text { 聚集区主要分布在 } \\
\text { 大公岛与竹岔岛连 } \\
\text { 线附近海域 }\end{array}$ & $\begin{array}{c}\text { 聚集区最近处距离 } \\
\text { 大公岛 } 10 \text { 海里以 } \\
\text { 内 }\end{array}$ & $\begin{array}{c}\text { 聚集区最近处距离 } \\
\text { 灵山岛 } 10 \text { 海里以 } \\
\text { 内 }\end{array}$ \\
\hline $\begin{array}{c}\text { 预计未来对海 } \\
\text { 域影响 }\end{array}$ & $\begin{array}{c}\text { 预计未来 } 3 \text { 天内将影响 } \\
\text { 主要社会敏感海域 (如 } \\
\text { 海上重大活动海域、风 } \\
\text { 景旅游区、海洋自然保 } \\
\text { 护区等)。 }\end{array}$ & $\begin{array}{c}\text { 预计未来 } 7 \text { 天内将 } \\
\text { 大规模进入青岛市 } \\
\text { 区南部海域, 并可 } \\
\text { 能影响管辖的社会 } \\
\text { 敏感海域 (如海上 } \\
\text { 重大活动海域、风 } \\
\text { 景旅游区、海洋自 } \\
\text { 然保护区等) }\end{array}$ & $\begin{array}{c}\text { 预计未来将 } 10 \text { 天 } \\
\text { 内大规模进入大公 } \\
\text { 岛以北海域, 并可 } \\
\text { 能影响管辖的社会 } \\
\text { 敏感海域 (如风景 } \\
\text { 旅游区、海洋自然 } \\
\text { 保护区、主要海水 } \\
\text { 养殖区等) }\end{array}$ & $\begin{array}{l}\text { 预计未来 } 20 \text { 天内 } \\
\text { 将大规模进入灵山 } \\
\text { 岛附近海域, 并可 } \\
\text { 能影响管辖的社会 } \\
\text { 敏感海域 (如主要 } \\
\text { 海水养殖区、海洋 } \\
\text { 自然保护区、风景 } \\
\text { 旅游区等)。 }\end{array}$ \\
\hline
\end{tabular}

\section{3. 水母灾害预警报方法研究}

对于外来型水母, 青岛第一海水浴场和电厂取 水口预警范围分为监视区和预警区（图 1), 根据船 舶航行一天往返实际距离为依据, 设置监视区域最 大范围距离岸边 $40 \mathrm{~km}$ 以内 (图 1, 蓝色)。根据示 范区一个潮周期最大运移距离为依据, 设置海水浴 场和电厂取水口预警区 (图 1, 橙色线和粉色线所 包含的区域) 最远范围距离。

\section{1. 海水浴场水母灾害预报警报等级划分及颜色 表征}

对于外来型水母, 根据灾害水母种类、毒性、 分布密度等指标, 结合水母发生区域和到达预警区 时间, 将水母灾害预警分为 4 级, 各级警报分别用 红、橙、黄、蓝等四种颜色表征其预警程度 (表 3)。 利用数值模式模拟未来对敏感海域的影响, 这也经 常用于防洪、绿潮等灾害预警中 [13]。当水母灾害 监测区内出现水母单点最大密度大于或等于 1 (个)
公顷), 对水母进行漂移预测, 并发布海水浴场水母 灾害预报产品。

1) 水母灾害红色警报: 当监测区内出现有毒水母 单点最大分布密度大于或等于 5000 (个/公顷) 或者无毒水母单点最大分布密度大于或等于 10000 (个/公顷), 预计未来 1 天内对预警区 (海 水浴场) 构成影响时, 发布水母灾害红色警报。

2) 水母灾害橙色警报：当监测区内出现有毒水母 单点最大分布密度大于或等于 500 (个/公顷) 或者无毒水母单点最大分布密度大于或等于 1000 (个/公顷), 预计未来 2 天内对预警区 (海 水浴场) 构成影响时, 发布水母灾害橙色警报。

3) 水母灾害黄色警报: 当监测区内出现有毒水母 单点最大分布密度大于或等于 50 (个/公顷) 或者无毒水母单点最大分布密度大于或等于 100 (个/公顷), 预计未来 3 天内对预警区 (海 水浴场) 构成影响时, 发布水母灾害黄色警报。

4) 水母灾害蓝色警报: 当监测区内出现有毒水母 单点最大分布密度大于或等于 5 (个/公顷) 或 者无毒水母单点最大分布密度大于或等于 10 (个/公顷), 预计未来 4 天内对预警区 (海水 
Risk Analysis and Crisis Response in Big Data Era (RAC-16)

浴场）构成影响时，发布水母灾害蓝色警报。

3.2. 电厂取水口水母预报警报等级划分及颜色表 征

对于外来型水母, 根据灾害水母的种类、密度 等指标, 结合水母发生的区域、可能到达预警区时 间, 结合青岛电厂取水口特征, 将水母预报警报分 为 4 个等级, 其中各级警报分别用红、橙、黄、蓝 等四种颜色表征其预警程度 (表 4)。当监测区内出 现水母单点最大分布密度大于或等于 20 (个/公顷), 对水母进行漂移预测, 同时发布电厂取水口水母灾 害预报产品。

1) 水母红色警报:当监测区内出现水母单点最大 密度大于或等于 20000 (个/公顷), 预计未来 1 天内对预警区（电厂取水口）构成影响时, 发 布水母红色警报。

2) 水母橙色警报: 当监测区内出现水母单点最大密

表 3 青岛海水浴场水母预警级别

\begin{tabular}{|c|c|c|c|c|c|c|c|c|}
\hline \multirow{3}{*}{$\begin{array}{l}\text { 指标 } \\
\text { 毒性 } \\
\end{array}$} & \multicolumn{8}{|c|}{ 海水浴场水母预警级别 } \\
\hline & \multicolumn{2}{|c|}{ 红色警报 } & \multicolumn{2}{|c|}{ 橙色警报 } & \multicolumn{2}{|c|}{ 黄色警报 } & \multicolumn{2}{|c|}{ 蓝色警报 } \\
\hline & 有毒 & 无毒 & 有毒 & 无毒 & 有毒 & 无毒 & 有毒 & 无毒 \\
\hline $\begin{array}{l}\text { 分布密度 (个 } \\
\text { /公顷) }\end{array}$ & 5000 & 10000 & 500 & 1000 & 50 & 100 & 5 & 10 \\
\hline $\begin{array}{l}\text { 影响预警区 } \\
\text { 时间（天） }\end{array}$ & $\leq 1$ & $\leq 1$ & $\leq 2$ & $\leq 2$ & $\leq 3$ & $\leq 3$ & $\leq 4$ & $\leq 4$ \\
\hline
\end{tabular}

表 4 青岛电厂取水口水母预警级别

\begin{tabular}{lllll}
\hline \multirow{2}{*}{ 指 标 } & \multicolumn{4}{c}{ 电厂取水口预警级别 } \\
\cline { 2 - 5 } & 红色警报 & 橙色警报 & 黄色警报 & 蓝色警报 \\
\hline $\begin{array}{l}\text { 分布密度 } \\
\text { (个/公顷 })\end{array}$ & $\geqslant 20000$ & $\geqslant 2000$ & $\geqslant 200$ & $\geqslant 20$ \\
\hline $\begin{array}{l}\text { 预计影响预警 } \\
\text { 区时间 }\end{array}$ & $\leqslant 1$ & $\leqslant 2$ & $\leqslant 3$ & $\leqslant 4$ \\
\hline
\end{tabular}

\section{4. 水母灾害风险等级预警方法应用}

2013 年 7 月 18 日在青岛黄岛一胶南外海发现沙海 掹, 密度 1.1 个/公顷, 利用水母监测信息和业务化运 行的海洋大气环境动力场, 启动水母应急漂移集合预 测模型[14], 结果发现沙海哲主要向偏北方向运动, 经过胶州湾口, 影响胶州湾附近海域。从不同时刻影 响范围（图 1) 可以看出水母（沙海哲）第一、二天 未影响到第一海水浴场预警区, 第三天开始进入第一 海水浴场预警区, 并影响到电厂取水口预警区, 第四 天开始进入电厂取水口预警区, 发布水母灾害预报。
度大于或等于 2000 (个/公顷), 预计未来 2 天内 对预警区 (电厂取水口) 构成影响时, 发布水母 橙色警报。

3) 水母黄色警报: 当监测区内出现水母单点最大密 度大于或等于 200 (个/公顷), 预计未来 3 天内 对预警区（电厂取水口）构成影响时, 发布水母 黄色警报。

4) 水母蓝色警报: 当监测区内出现水母单点最大密 度大于或等于 20 (个/公顷), 预计未来 4 天内对 预警区（电厂取水口）构成影响时, 发布水母蓝 色警报。

图 122013 年 7 月 18 日水母装集合预报未来 4 天影响范围 


\section{Risk Analysis and Crisis Response in Big Data Era (RAC-16)}

\section{5. 结论}

本文借鉴国内海洋生态灾害 (赤潮、绿潮等) 应急响 应及预报警报标准, 初步建立了外来型水母灾害风险 等级预警方法。该方法针对外来型水母, 根据灾害水 母的种类、密度等指标, 结合水母发生的区域、预计 标准类似, 可以采用数值模拟方法进行漂移预 测。该方法将在未来水母灾害监测和预测预警示范应 用中逐步改进, 也可在其他海域的海水浴场和电厂取 水口进行适用和推广, 也为原发型水母的预警方法的 研究提供参考。水母预警方法研究可为今后水母灾害

\section{Acknowledgements}

This study was supported by the National Special Research Fund for Non-Profit Marine Sector (No. 201005018) and open found of Key Laboratory of Ocean Circulation, Institute of Oceanology, Chinese Academy of Science (KLOCAW1403).

\section{致谢}

本研究得到了国家海洋局海洋公益性行业科研专项 (201005018)和中国科院海洋环流与波动重点实验室 开放基金(KLOCAW1403)。

\section{参考文献}

[1] Brodeur, R D, C E Mills, J E Overland, et al. Evidence for a substantial increase in gelatinous zooplankton in the Bering Sea, with possible links to climate change. Fish Oceanogr., 1999, 8(4): 296-306.

[2] Mills, C E. Jellyfish blooms: are populations increasing globally in response to changing ocean conditions?. Hydrobiologia, 2001, 451: 55-68.

[3] Nagai T. Recovery of fish stocks in the Seto Inland Sea. Mar. Pollut. Bull., 2003, 47: 126-131.

[4] Greve W. The 1989 German Bight Invasion of Muggiaea Atlantica. ICES J. Mar. Sci., 1994, 51(4): 355-358.

[5] 程家骅, 李圣法, 丁峰元, 严利平. 东、黄海大型 水母暴发现象及其可能成因浅析. 现代渔业信息, 2004, 19(5): 10-12.

[6] Moon, J H, I C Pang, J Y Yang, W D Yoon. Behavior of the giant jellyfish Nemopilema nomurai in the East China Sea and East/Japan Sea during the
未来到达预警区时间, 分析青岛电厂取水口或海水浴 场等典型海域特征, 将水母预警报分为 4 个等级。该 方法预计未来到达预警区的时间与绿潮警报

预警报标准的建立提供基础, 使水母灾害预警报更科 学化、标准化、制度化, 有利于绿潮灾害的准确分级 和预警报的及时发布, 对我国管辖海域的绿潮监测和 预警业务有重要的科学意义和实际应用价值, 对保护 海洋环境有重要意义。

summer of 2005: A numerical model approach using a particle-tracking experiment. Journal of Marine Systems, 2010, 80(1-2): 101-114.

[7] Kyounghoon, L, B S Bae, I O Kim, W D Yoon. Measurement of swimming speed of giant jellyfish Nemopilema nomurai using acoustics and visualization analysis. Fisheries Science, 2010, 76(6), 893-899.

[8] Brown C W, R R Hood, Z Li, M B Decker, T F Gross, J E Purcell, H V Wang. Forecasting system predicts presence of sea nettles in Chesapeake Bay. Eos, Transactions American Geophysical Union, 2002, 83(30): 321-326.

[9] Berline L, B Zakardjiana, A Molcarda, Y Ourmièresa, K Guihoua. Modeling jellyfish Pelagia noctiluca transport and stranding in the Ligurian Sea. Marine Pollution Bulletin, 2013, 70(1): 90-99.

[10]王世伟, 张光涛, 孙 松等. 2011 年夏季胶州湾 三种大型水母的种群动态研究, 海洋与湖沼, 2012, 43(3), 471-479.

[11]孙 松. 对黄、东海水母暴发机理的新认知, 海洋 与湖沼, 43(3),406-410.

[12]张海彦, 赵 亮, 魏皓. 青岛外海夏季水母路径溯 源研究, 海洋与湖沼, 2012, 43(3), 662-668.

[13] Li S J, Xie Y X. Utilization of Flood Simulation Technique in Urban Flood Warning-A Case Study on Fuzhou. Journal of Risk Analysis and Crisis Response, 5(2), 2015, 120-128.

[14]吴玲娟, 高松, 刘桂艳, 白涛. 青岛近海大型水 母漂移集合预测方法研究. 海洋预报, 2015, 32(2): 62-71. 